\title{
MECHANICAL PROPERTIES AND NATURE OF CRACKING FeAI ALLOYS
}

\author{
Janusz CEBULSKI, Dorota PASEK \\ Silesian University of Technology, Katowice, Poland, EU, \\ janusz.cebulski@polsl.pl; dorota.pasek@polsl.pl
}

https://doi.org/10.37904/metal.2019.922

\begin{abstract}
This article describes mechanical properties such as tensile strength, yield strength, impact resistance and correlation between conditions determining the breakthrough and nature Fe40Al5Cr0.2TiB alloy. The breakthroughs obtained during the tests of mechanical properties were carry out by scanning electron microscopy (SEM). Insufficient plasticity at ambient temperatures and a tendency to brittle fracture make the material vulnerable to brittle fracture, and breakthroughs in areas with plastic deformation differ by their morphology from the ductile fractures found in conventional construction materials. The intention of the authors was to classify the breakthroughs of FeAl intermetallic alloys based on the mechanism of their formation.
\end{abstract}

Keywords: FeAl alloys, mechanical properties, structure, cracking

\section{INTRODUCTION}

The alloys based on intermetallic phases are characterized by an ordered internal structure and properties resulting from the occurrence of three types of bonds: metallic, ionic and covalent [1-4]. The energy of binding of two different atoms is greater than the bonds between the same elements in the alloy, which ensures ordering the structure of the solution. A significant share of aluminum in the composition of alloys based on intermetallic phases provides these materials, owing to the intrinsically tight protective layers that form, a high heat resistance to corrosion of the aggressive environment [5-7]. Aluminum and titanium also determine their low density with relatively high strength and high modulus of lateral elasticity. The FeAl intermetallic phases containing 36 at $\%$ to 51 at $\%$ of aluminum have stable properties over a wide temperature range [1-5]. They are also characterized by a low density of $5.5 \mathrm{~g} / \mathrm{cm}^{3}$, high corrosion resistance compared to traditional construction materials, aggressive environments, seawater, carburizing, sulfur and very good tribological properties at elevated temperature. Fe-Al alloys have found wide application in many branches of industry, such as energy, air and petrochemical [6-8]. In the automotive industry, they can be used as elements of a hot turbocharger part, rings, catalyst elements $[9,10]$. Due to low material costs and satisfactory properties, these alloys can replace some steels containing chromium and nickel. The development of methods for joining these alloys would expand the range of their application, e.g. as elements of combustion engines [11].

\section{RESEARCH MATERIAL AND METHODOLOGY}

The test material was an alloy based on the Fe40AI5Cr0.2TiB at\% intermetallic phase after casting, the chemical composition of which is summarized in Table 1. The pure metals were used to melt the alloy: Armco iron (technically pure), Aro aluminum (99.995 wt\% pure), aluminothermic chromium obtained by the Kroll method and amorphous boron (chemically pure). The alloy was modified with an alloy additive, which was designed to improve strength and plastic properties ( $5 \mathrm{wt} \% \mathrm{Cr}$ ). The melts were carried out in the Balcerss VSG-2 induction vacuum furnace. Smelting was carried out in a vacuum $\left(10^{-2} \mathrm{~Pa}\right)$ and casting into cold graphite molds. Then it was subjected to annealing at $1000{ }^{\circ} \mathrm{C}$ for 48 hours, cooling with the furnace, which was supposed to homogenize the structure. Some of the bars were mechanically machined up to $\varphi=12 \mathrm{~mm}, I=$ $120 \mathrm{~mm}$, and the rest were plastically processed with a rolling mat from dimensions $\varphi=20 \mathrm{~mm}$ to $\varphi=10 \mathrm{~mm}$. The test pieces for strength tests were made of annealed rods and plastically processed. The mechanical 
properties were determined in the uniaxial stretching test on the MTS ending machine. The test was carried out at room temperature and elevated on samples with a measuring base $I=30 \mathrm{~mm}$ and a diameter of $6 \mathrm{~mm}$. After strength testing, breakthroughs were observed using the Hitachi S4200 scanning electron microscope along with EDS X-ray microanalysis.

Table 1 Chemical composition of Fe40AI5Cr0.2TiB alloy (atomic \%)

\begin{tabular}{|c|c|c|c|c|c|}
\hline Content of element & Al & Cr & Ti & B & Fe \\
\hline & 40.22 & 4.87 & 0.21 & 0.011 & rest \\
\hline
\end{tabular}

\section{EXPERIMENTAL RESULTS}

The basic mechanical characteristics of the tested alloy were determined, ie. $R_{e}, R_{m}$, and $A_{5}$ (Table 2). They indicate low plasticity in the case of the cast material regardless of the temperature of the tensile test, while the plastic working significantly improves the mechanical properties of Fe40AI5Cr0.2TiB alloy. The increase in tensile strength obtained through plastic working, combined with the appearance of the yield point results from the removal of casting defects, mainly dendrites, which in the tested alloy occur in a particularly large proportion, which has been demonstrated on the basis of a static tensile test using a scanning electron microscope (Figures 1-4). Performing a static tensile test both at room temperature and at $600{ }^{\circ} \mathrm{C}$ resulted in maintaining this tendency, and the crack surfaces revealed the presence of a dendritic structure on the large surface area of the alloys after crystallization. Diversification of the chemical composition in dendritic areas was also demonstrated, resulting in a decrease in the aluminum content in dendrites in relation to areas outside dendrites. The high-melting components crystallizing in dendrites cause a decrease in the concentration of $\mathrm{Al}$ to a value below determining the formation of the FeAl phase, which condition the occurrence of the $\mathrm{Fe}_{3} \mathrm{Al}$ phase. Surface distributions of elements depict the distribution of individual elements associated with the segregation of chemical composition in the areas of grains and dendrites. Segregation of the chemical composition conditioning the formation of various intermetallic phases after crystallization results in the material being exposed to degradation of structure and properties in a way that is difficult to predict. These studies confirm previous analyzes and own research conducted on alloys from the Fe-Al system, the results of which clearly indicate that except for a few cases of practical applications, the intermetallic FeAl alloy for utilitarian purposes must undergo plastic processing. The few cases in which the interstellar alloys can be used, whose matrix is the FeAl phase concern elements of small dimensions usually made by EDS methods (Figure 5-6), less frequently by other post-treatment techniques, should be made from ingot areas with the smallest number of casting defects from the part devoid of dendrites. Areas with the smallest amount or poisoned dendrites occur outside the axis of the ingot, however, they are characterized by coarseness, which additionally favors the fracture of alloys from the Fe-Al system. For the above reasons, plastic processing is justified, but requires the use of advanced technologies, with strictly defined process parameters, much more stringent than in the case of commonly used engineering materials.

Table 2 Mechanical properties of Fe40Al5Cr0.2TiB alloy

\begin{tabular}{|c|c|c|c|}
\hline $\begin{array}{c}\text { Type of alloy / temperature of the tensile } \\
\text { test }\end{array}$ & $\begin{array}{l}\text { Offset yield } \\
\text { strength } R_{e}(\mathrm{MPa})\end{array}$ & $\begin{array}{l}\text { Tensile strength } \\
R_{m}(\mathrm{MPa})\end{array}$ & $\begin{array}{c}\text { Relative elongation } \\
A_{5}(\%)\end{array}$ \\
\hline Alloy after crystallization / room temperature & - & 256 & - \\
\hline Alloy after rolling / room temperature & 398 & 458 & - \\
\hline Alloy after crystallization / temperature $600^{\circ} \mathrm{C}$ & - & 240 & - \\
\hline Alloy after rolling / temperature $600^{\circ} \mathrm{C}$ & 387 & 421 & 5 \\
\hline
\end{tabular}



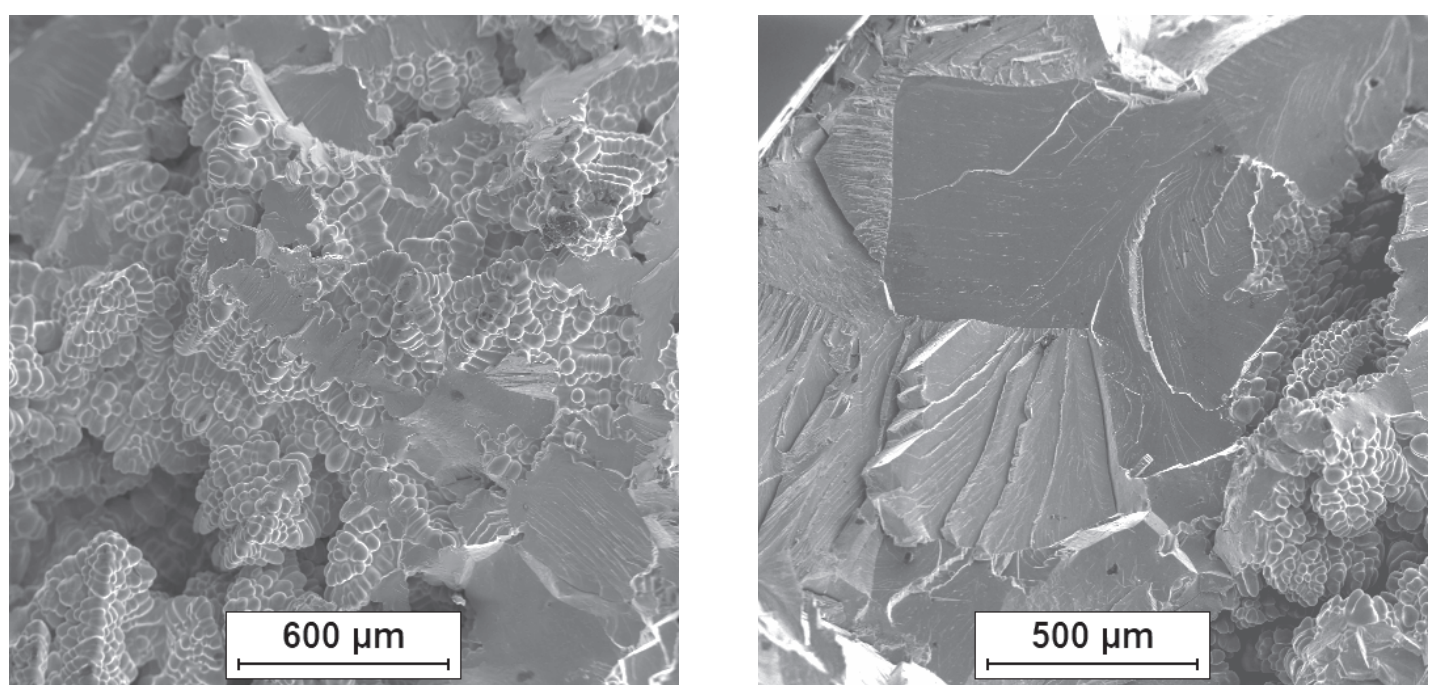

Figure 1 Fracture surface, cast material, static test of stretching the ambient temperature
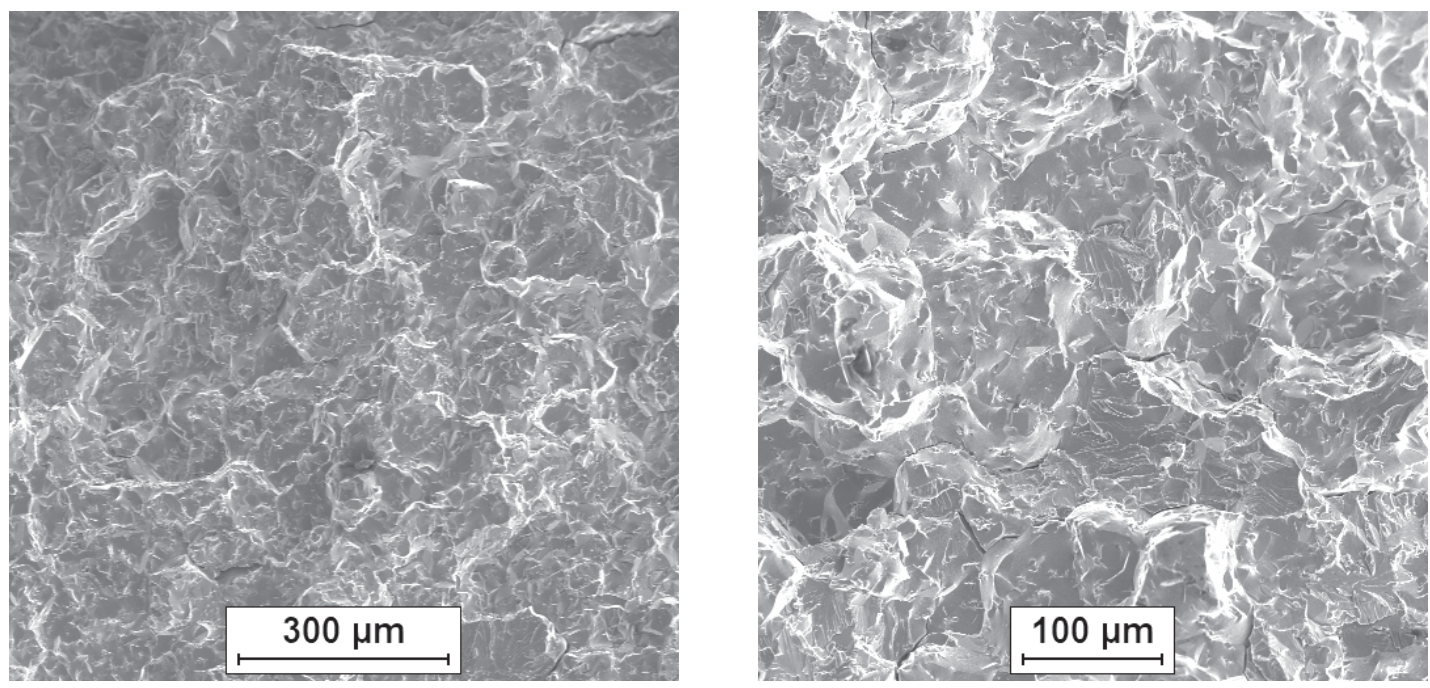

Figure 2 Fracture surface after rolling, static test of stretching the ambient temperature
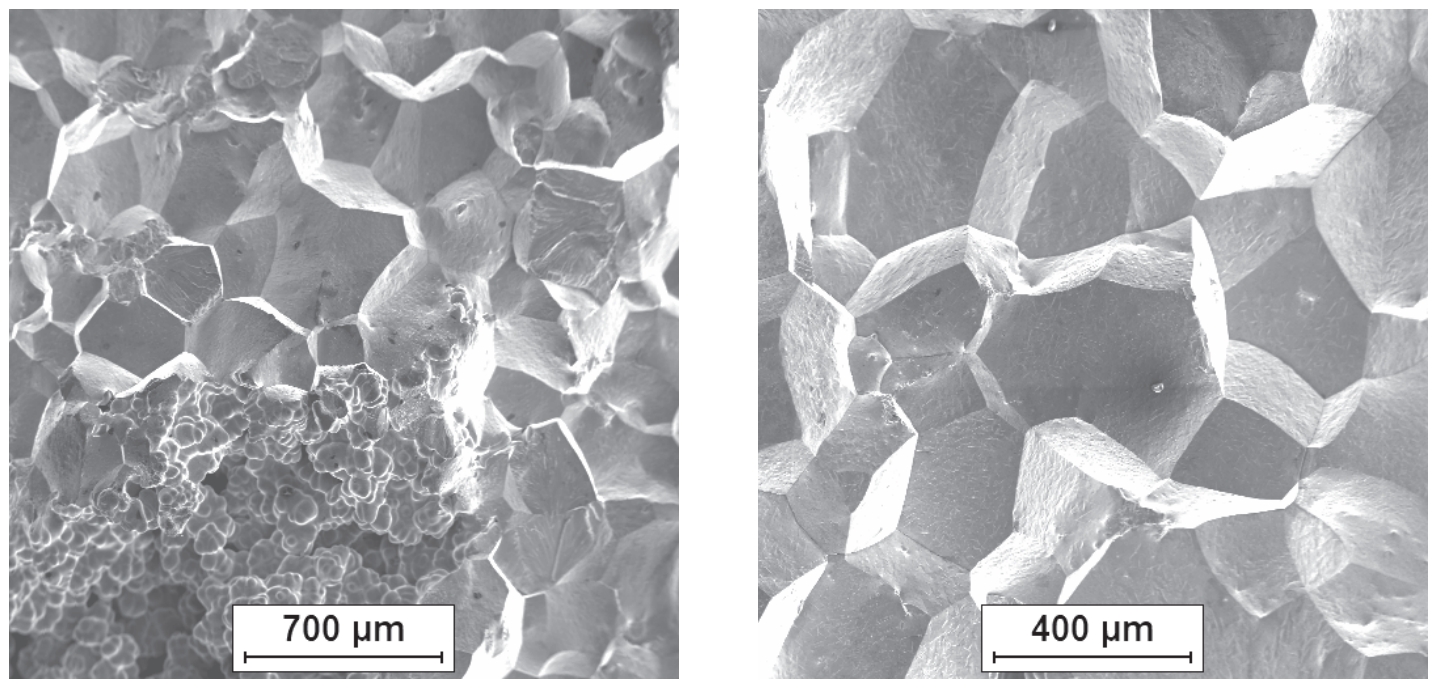

Figure 3 Fracture surface cast material, static tensile test at $600{ }^{\circ} \mathrm{C}$ 

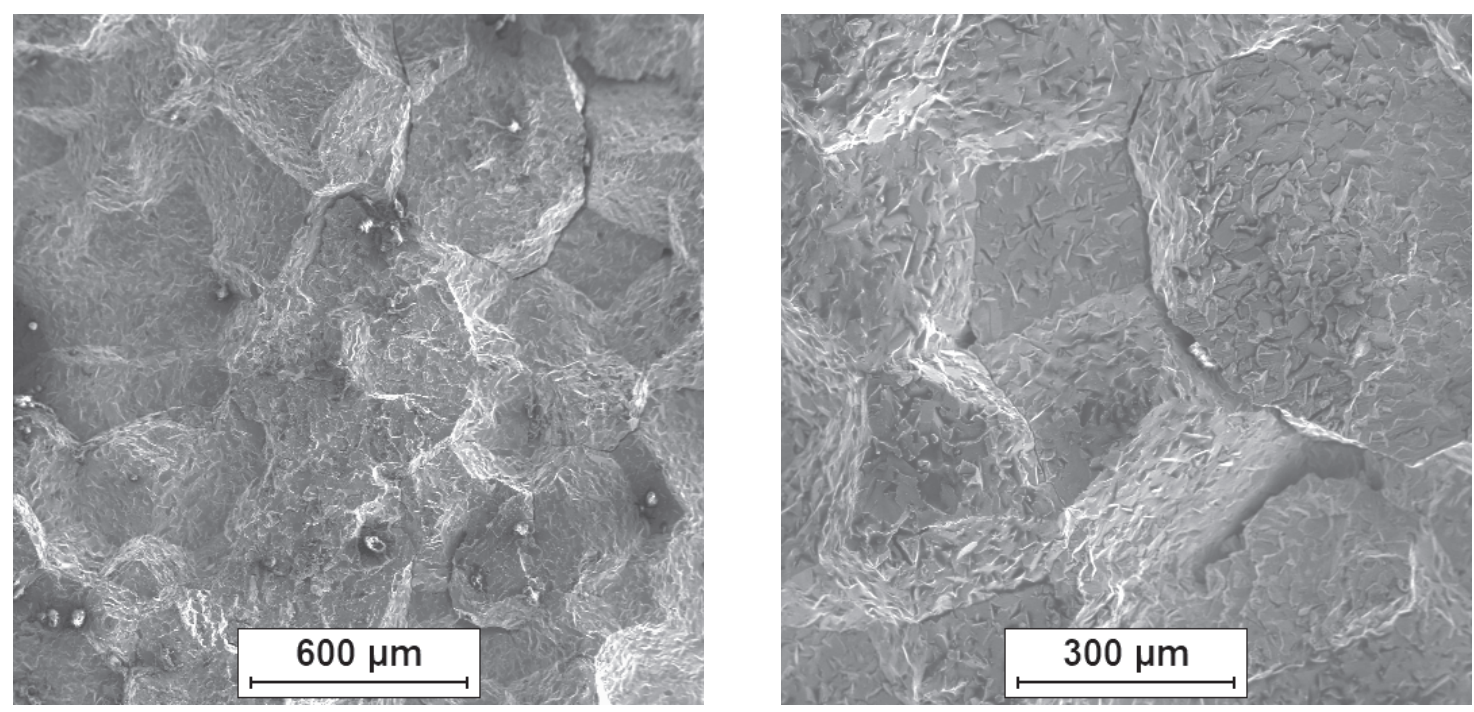

Figure 4 Fracture surface, rolling material, static tensile test at $600{ }^{\circ} \mathrm{C}$

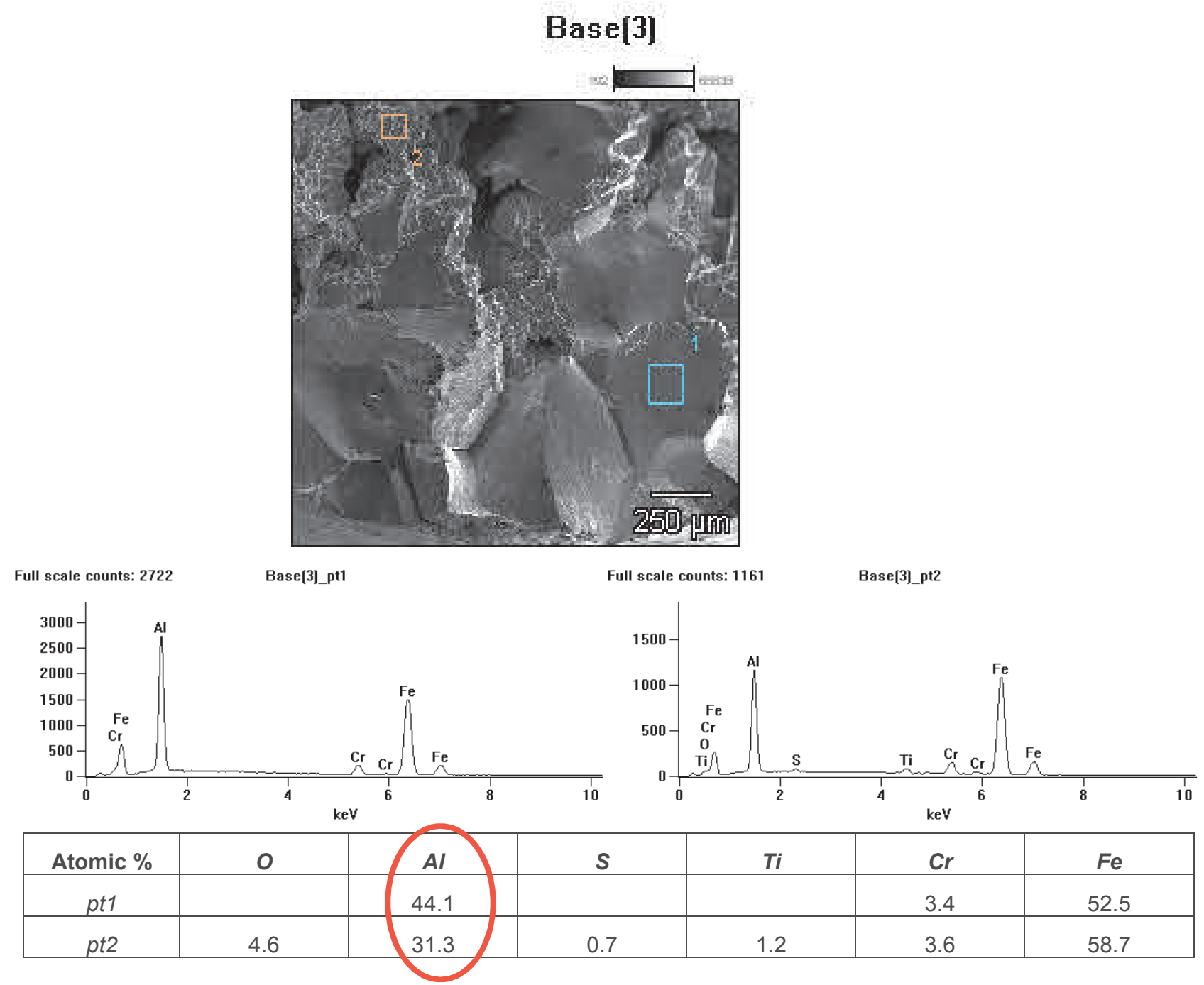

Figure $5 \mathrm{X}$-ray microanalysis of chemical composition of material fracture surface after casting and static tensile test at ambient temperature 

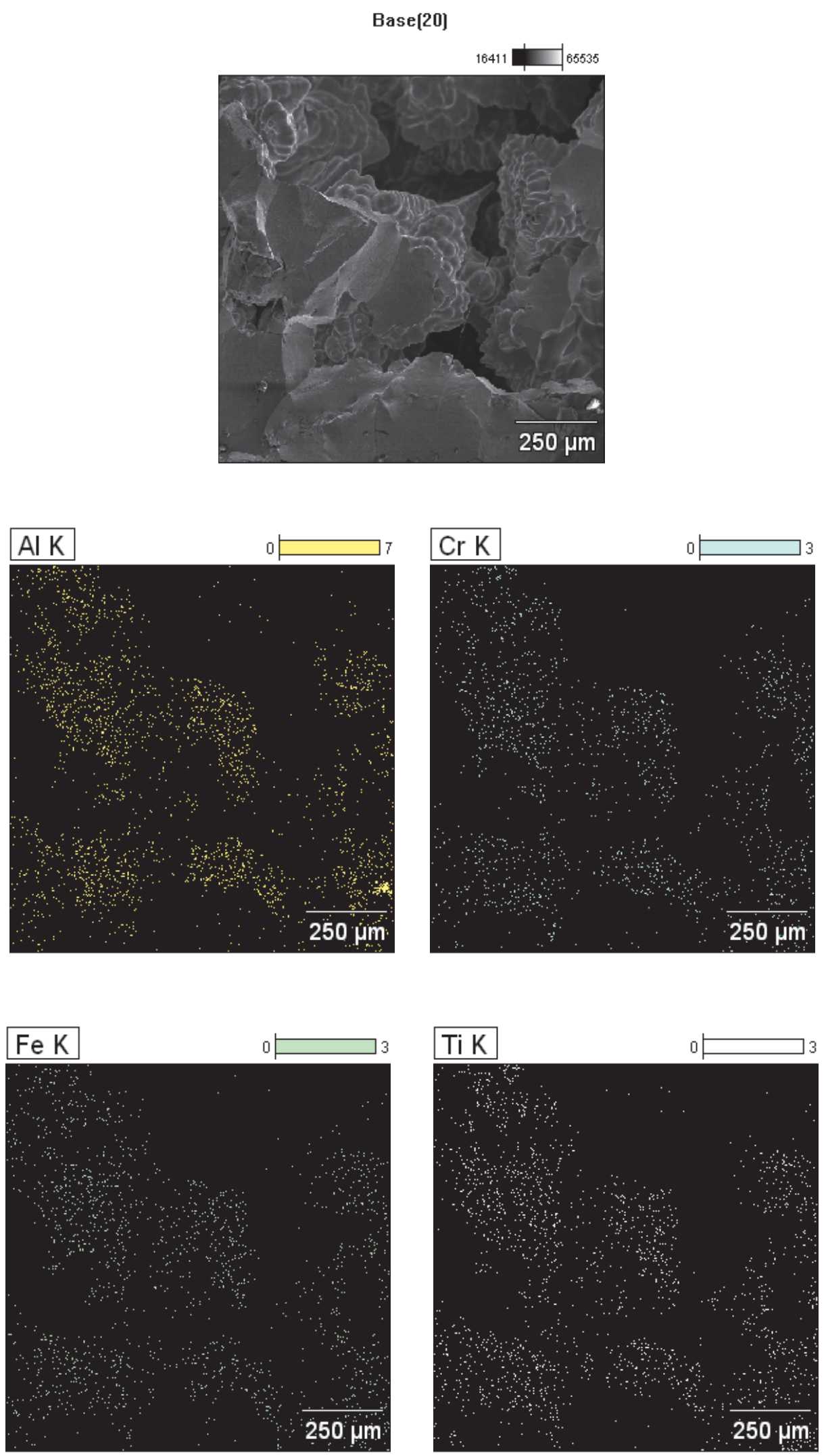

Figure 6 Distribution of chemical elements of material after casting and static tensile test in ambient temperature 


\section{CONCLUSION}

The intermetallic alloy Fe40AI5Cr0.2TiB is characterized by high susceptibility to brittle fracture, especially in the state after crystallization. This is due not only to the crystalline B2 type but also to the occurrence of dendritic structure and coarseness. As demonstrated in this work, plastic working causes a significant improvement in mechanical properties mainly due to the removal of the dendritic structure, and thus an increase in the cross-section of the material during mechanical stress. It is particularly important to reduce the heterogeneity of the chemical composition because the formation of the $\mathrm{Fe}_{3} \mathrm{Al}$ phase during the crystallization involves a local decrease in the material's high-temperature corrosion resistance [4]. Studies have shown that in dendrites aluminum concentration falls below the value determining the formation of the alloy, whose matrix is the FeAl phase. The breakthroughs of the plastically processed material, after a static tensile test, show a homogeneous brittle fracture without the presence of dendrites.

\section{ACKNOWLEDGEMENTS}

The paper is financed from funds within the scope of work No. 11/990 / BK_19 / 0063.

\section{REFERENCES}

[1] HARAGUCHI, T., YOO, M.H., KATO, H., HANADA, S. and INOUE A. Vacancy clustering and relaxation behavior in rapidly solidified B2 FeAl ribbons. Acta Materialia. 2005. vol. 53, pp.3751-3764, http://dx.doi.org/10.1016/j.actamat.2005.04.027.

[2] BOJAR, Zbigniew and PRZETAKIEWICZ, Wojciech. Metal Materials Involving Intermetallic Phases, BEL Studio, Warszawa, 2006. pp. 89-110. (in Polish).

[3] JASIONOWSKI, Robert, PRZETAKIEWICZ Wojciech and ZASADA Dariusz. The effect of structure on the cavitational wear of Fe-Al intermetallic phase-based alloys with cubic lattice. Archives of Foundry Engineering. 2011. vol. 11, pp. 97-102.

[4] CEBULSKI, Janusz and PASEK, Dorota. Heat resistance of intermetallic phase matrix Fe-Al alloys in steam environment. In METAL 2017: 26th International Conference on Metallurgy and Materials. Ostrava: TANGER, 2014, pp. 1200-1206.

[5] BARCIK Jan, GIEREK Adam, KUPKA Marian and MIKUSZEWSKi Tomasz. Technological aspects of alloy production and casting on the FeAl type intermetallic matrix. Hutnik-metallurgical news. 2001. vol. 6, pp. 214-223. (in Polish).

[6] KUPKA, Marian. Structure and properties of alloys based on FeAl matrix obtained in metallurgical processes. University of Silesia Publishing House, Katowice, 2005. pp. 5-12. (in Polish).

[7] FRUTOS, E., MORRIS, D.G. and MUÑOZ-MORRIS, M. A. Evaluation of elastic modulus and hardness of Fe-Al base intermetallics by nano-indentation techniques. Intermetallics. 2013. vol. 38, pp. 1-3.

[8] GONTARZ, Grzegorz, GOLAŃSKI, Dariusz and CHMIELEWSKI, Tomasz. Properties Fe-Al type intermetallic layers produced by AC TIG method. Advances in Materials Science. 2013. vol. 13, no. 3, pp. 5-16.

[9] SKIBA, Tomas, HAUSILD, Petr, KARLIK, Miroslav, VANMEENSEL, Kim and VLEUGELS, Jozef. Mechanical properties of spark plasma sintered FeAl intermetallics. Intermetallics. 2010. vol. 18, pp. 1410-1414.

[10] TORTORELLI, P. and NATESAN, K. Critical factors affecting the high-temperature corrosion performance of iron aluminides. Material Science Engineering. 1998. vol. 258, pp. 115-125.

[11] CEBULSKI, Janusz. Application of FeAl intermetallic phase matrix based alloys in the turbine components of a turbocharger. Metalurgija. 2015. vol. 54, no. 1, pp. 154-156. 